\title{
Model tests of wind turbine with a vertical axis of rotation type Lenz 2
}

\author{
Jaroslaw Zwierzchowski ${ }^{1,{ }^{*}}$, Pawel Andrzej Laski ${ }^{1}$, Slawomir Blasiak ${ }^{1}$, Jakub Emanuel Takosoglu ${ }^{1}$, Dawid Sebastian \\ Pietrala $^{1}$, Gabriel Filip Bracha ${ }^{1}$, and Lukasz Nowakowski ${ }^{1}$ \\ ${ }^{1}$ Faculty of Mechatronics and Mechanical Engineering, Kielce University of Technology, Al. 1000-PP 7; 25 - 314 Kielce; PL
}

\begin{abstract}
A building design of vertical axis wind turbines (VAWT) was presented in the article. The construction and operating principle of a wind turbine were described therein. Two VAWT turbine models were compared, i.a. Darrieus and Lenz2, taking their strengths and weaknesses into consideration. 3D solid models of turbine components were presented with the use of SolidWorks software. Using CFD methods, the air flow on two aerodynamic fins, symmetrical and asymmetrical, at different angles of attack were tested. On the basis of flow simulation conducted in FlowSimulation, an asymmetrical fin was chosen as the one showing greater load bearing capacities. Due to the uncertainty of trouble-free operation of Darrieus turbine on construction elements creating the basis thereof, a 3D model of Lenz2 turbine was constructed, which is more reliable and makes turbine self-start possible. On the basis of the research, components were designed and technical docu mentation was compiled.
\end{abstract}

\section{Introduction}

Turbines convert kinetic energy into electrical energy using a rotor mounted on a shaft connected to the generator. Rotating turbine rotor decreases wind speed from $v_{1}$ before turbine to $v_{2}$ behind turbine. Difference between those two wind speeds is a processed measure value of kinetic energy of moving rotor connected with the generator of electricity. Generally, the maximum theoretical wind power can be calculated with assuming, that wind speed behind the turbine is equal to zero:

$$
P_{\text {max }, \text { theoretical }}=\frac{1}{2} \rho A U_{0}^{3},
$$

where: $\rho$ - air density, $U$ - wind speed, A - surface area reduction of wind speed.

In practice, it is impossible to reduce the wind speed behind the turbine to zero, therefore $C_{p}$ power factor is added into theoretical model. Power factor represents the ratio between the actual and maximum power. Theoretical $C_{p}$ maximum is labelled to Betz's limit and is equal to $16 / 27$ (or 0.593 ) [2]. In real condition power factor does not reach even 0.5. This fact is due to aerodynamic losses. $C_{p}$ factor reaches the maximum value when wind speed $v_{2}$ behind the turbine is equal to $1 / 3$ of $v_{1}$ before one.

\subsection{Aerodynamic properties}

When an object is exposed to the wind, it experiences impact of aerodynamic force. Occurrence of this force is caused by wind pressure and viscous friction between air and outer surface of the object. Aerodynamic force in the direction of the wind is called the drag. When streamline shape object, such as an aircraft wing panel, is exposed to the wind, the aerodynamic force is distributed on the two components:

- drag - component parallel to the air flow direction,

- lift - component perpendicular to the air flow direction. This is shown in Figure 1, where are moment and forces acting on wing in two-dimensional space.

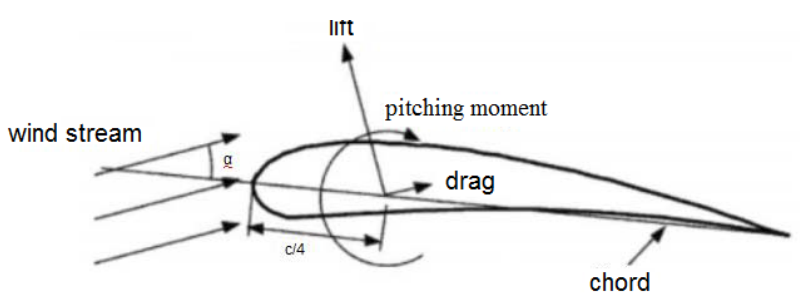

Fig. 1. Torque and forces acting on wing.

The flow velocity at the upper convex part of the panel is increased, it creates a low pressure area over the air panel in accordance with Bernoulli's principle. This will result in lift force that is perpendicular to the direction of the incoming air. The application point, where forces act, is considered on the chord, within 1/4 of the chord length from the leading edge. To describe the force as a whole there is added pitching moment which is generally located at the same reference point as components of forces [2].

Another characterizing parameter of the aerodynamic properties is tip-speed ratio, also known as specific speed ratio, defined as follows:

*Corresponding author: j.zwierzchowski@tu.kielce.pl 


$$
\lambda=u_{t} / U
$$

where: $u_{t}-$ the tangential component of the rotor speed, $U,-$ wind speed.

Flight speed factor is related to the $C_{p}$ power factor, whose optimal level is obtained for the specific TSR (tip-speed ratio). For devices operating on the basis of the drag, TSR will never exceed the value of 1 , but for aircraft wings or helicopter panels based on the strength of lift reaches higher values [1].

\subsection{VAWT turbine}

The first practical wind machines were windmills with vertical axis marketing invented in eastern Persia in the ninth century. Those turbines had a rod construction in which, were mounted sails made of sugar cane bundles as shown in Fig. 2.

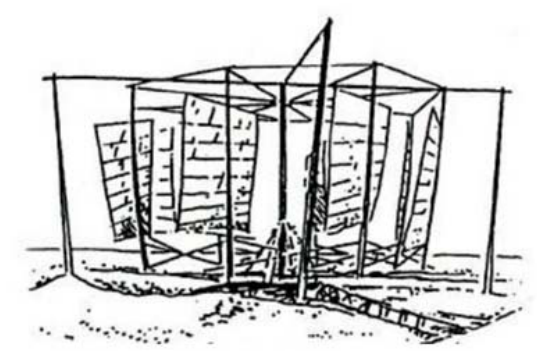

Fig. 2. Windmill on the vertical axis of the ninth century [6].

In modern times there have been developed several designs of vertical axis wind turbines (VAWT). Their main advantage is that the mechanical and electrical parts such the gear or generator can be installed close to the ground. This ensures greater economic efficiency in the tower construction and facilitates maintenance. Additionally, VAWT are non-directional, which means that they take the wind from all sides and do not need control mechanism deviations. Their drawback is the fact that most them work on lift strength must have automatic start-up. There is necessary external source power to carry the turbine in motion.

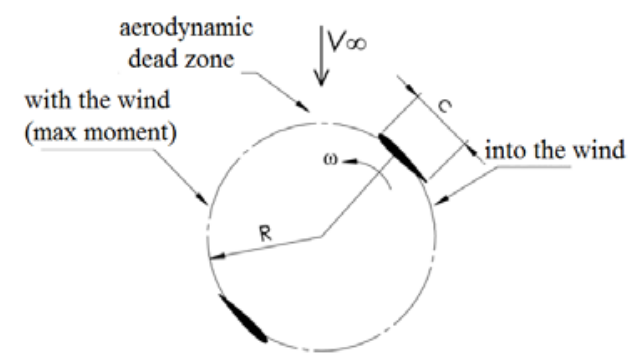

Fig. 3. VAWT - view from the top.

Performance of wind turbines with vertical axis is generally less compred to their horizontal counterparts because rotor panels during rotation pass through aerodynamic dead zone shown in Fig. 3.

\subsubsection{Type Darrieus}

H-Darrieus turbine (Type H-rotor) can be characterized by straight panels which, together create the letter $\mathrm{H}$. The model is shown in Fig. 4. It has improved efficiency, simpler construction and relatively high power unit. The rotor aerofoils are spaced up from the center of the turbine, so that the rotation continuously changes the attack angle relative to the wind. However, when one of the blades is operated with the wind, the second opposed resists. This in consequence reduces the efficiency of the design.

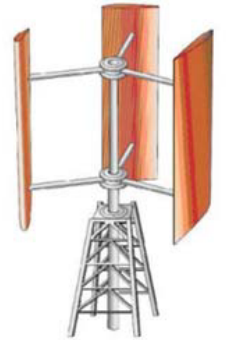

Fig. 4. Turbine $\mathrm{H}$ - rotor [3].

\subsubsection{Type Lenz}

All wind turbines type VAWT were inspired by two basic types: Savonius'a and Darrieus'a. In 2007, was published an article of a wind turbine with greater efficiency of approx. $40 \%$ compare to ones above. This turbine was invented by Ed Lenz. The project introduced a lot of innovation, for example he combined Darrieus turbine working on the aerodynamic lift force and Savonius turbine relying on the drag (see Fig 5).

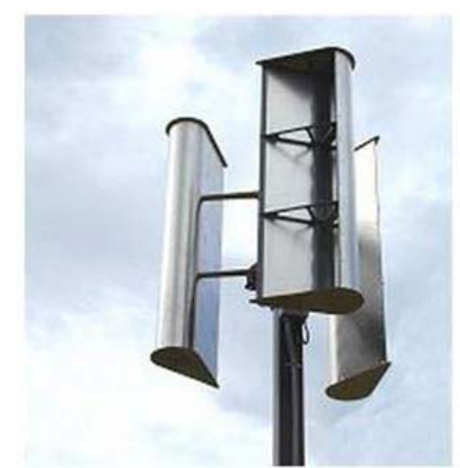

Fig. 5. VAWT turbine Lenz2 type [5].

Tip speed ratio of the turbine described in the article is between 0.8 and 1.2 at wind speeds of $6.7 \mathrm{~m} / \mathrm{s}$. This means that the turbine uses the lift force. The rotational speed of the turbine should be approx. $130 \mathrm{r} / \mathrm{min}$.

\section{Simulation studies and model construction}

CFD analysis of two turbine aerofoils Darrieus NACA0012 and NACA4415 (Fig. 6) was carried out using Flow Simulation module, which is an integral part of the SolidWorks. When comparing the two aerodynamic panels $C_{l}$ lift coefficient was obtained for different wind wings attack angles ranging from $0^{\circ}$ to $18^{\circ}$. It allows to select optimum wing attack angle. It was also a pressure factor distribution and velocity 
distribution calculated around the wing. Those two wings were inspired by a model from the windgenkits.com website with modifications using SolidWorks 3D.

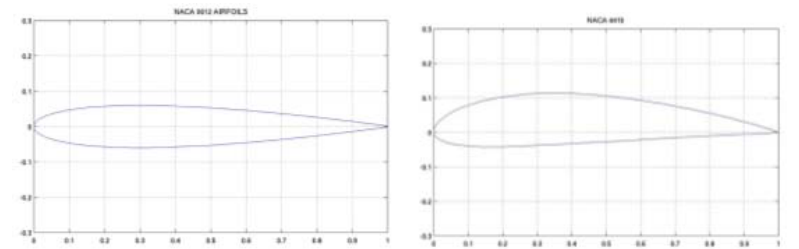

Fig. 6. Geometry of aerofoil: a) NACA 4415, b) NACA 0012 [4].

The main parameters that characterize those aerofoils are a chord length $c$ (chord) and the thickness, which is a function of the length. For aerofoil NACA0012 its thickness is $12 \% c$. The second aerofoil is asymmetrical profile NACA4415. It is often used for testing and simulation. Its thickness is $15 \%$ c. In the next part of the paper is compared pressure distribution in upper and lower sections of both panels using different attack angles.

The rotational speed $\omega$ is represented by a factor of flight $\lambda$ (TSR). This parameter is expressed as the ratio of airfoil speed to the of $V_{\text {in }}$ air stream speed:

$$
\lambda=\frac{\omega \cdot R}{V_{\text {in }}}
$$

Power factor $C_{p}$ is determined experimentally by measuring the power produced by the turbine and dividing it by the theoretical turbine power, which is calculated from formula (2):

$$
C_{p}=\frac{P}{\frac{1}{2} \rho A U^{3}} .
$$

The wind speed is set to $5 \mathrm{~m} / \mathrm{s}$. Pressure, temperature and humidity are average values. The analysis was performed for several angles of attack to determine the appropriate position of the aerofoil relative to the inflowing air stream. It was done in order to compare the properties and behaviour of both wings. Simulation parameters are stored in Table 1.

Table 1. Simulation parameters

\begin{tabular}{|c|c|}
\hline angle of attack & $0^{\circ}, 2^{\circ}, 4^{\circ}, 6^{\circ}, 8^{\circ}, 10^{\circ}, 12^{\circ}, 14^{\circ}, 16^{\circ}, 18^{\circ}$ \\
\hline wind speed & $5 \mathrm{~m} / \mathrm{s}$ \\
\hline type analysis & Outside \\
\hline flow model & turbulent and laminar; model: k- $\varepsilon$ \\
\hline Pressure & $101325 \mathrm{~Pa}$ \\
\hline Temperature & $293.2 \mathrm{~K}$ \\
\hline Humidity & $50,00 \%$ \\
\hline
\end{tabular}

\subsection{Simulation parameters - Darrieus turbine}

Due to contours of pressure distribution and velocity vectors the point of stagnation is shown. Fig. 5a shows equal pressure distribution on both sides of the airfoil due to its symmetry. The values in the upper left corner of drawings is a dimensionless coefficient of pressure distribution calculated from the formula

$$
C_{p}=\frac{p_{i}-p}{\frac{1}{2} \rho U^{2}}
$$

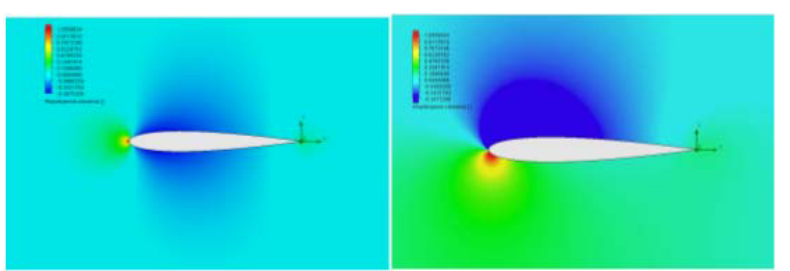

Fig. 7. NACA0012 pressure distribution for the angle of: a) $0^{\circ}$, b) $10^{\circ}$.

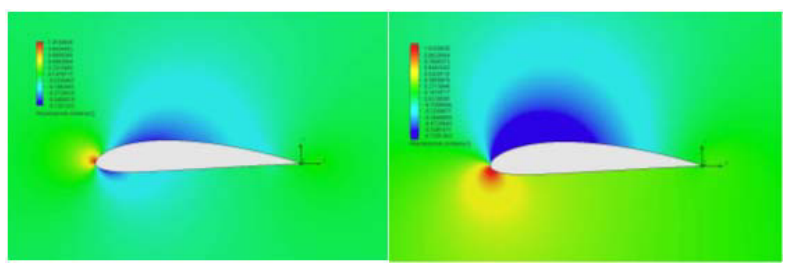

Fig. 8. NACA4415 pressure distribution for the angle of: a) $0^{\circ}$, b) $10^{\circ}$.

Fig. $7 \mathrm{~b}$ shows a pressure distribution for the attack angle of $10^{\circ}$, There is in upper side of the airfoil elevated pressure zone, the stagnation point is moved down. If attack angle increases airfoil lump becomes less streamlined. The same can be seen with panel, with the difference that the pressure difference for asymmetric airfoil is higher than for symmetrical one (see Fig. 8).

The most important parameter obtained through simulation is lift $L$, actually, lift coefficient $C_{l}$. For example, from Fig. 7a lift $L=9,047798 e-006[N]$. The $L$ value can be read from Table 2 , there are surface parameters exported from FlowSimulation. Lift coefficient is from formula

$$
C_{l}=\frac{L}{\frac{1}{2} \rho U^{2} b c}=0.00050102 .
$$

Table 2. Simulation parameters - surface parameters.

\begin{tabular}{|l|l|l|r|}
\hline Parameter & Minimum & Maximum & Average \\
\hline Pressure $[\mathrm{Pa}]$ & 101319,46 & 101344,85 & 101322,60 \\
\hline $\begin{array}{l}\text { Density (Fluid) } \\
{\left[\mathrm{kg} / \mathrm{m}^{\wedge} 3\right]}\end{array}$ & 1,2004570 & 1,2007300 & 1,2004885 \\
\hline Shear Stress [Pa] & 0 & 0,6173043 & 0,1277972 \\
\hline $\begin{array}{l}\text { Temperature } \\
\text { (Fluid) [K] }\end{array}$ & 293,19976 & 293,21306 & 293,2069 \\
\hline $\begin{array}{l}\text { Relative Pressure } \\
{[\mathrm{Pa}]}\end{array}$ & $-5,531395$ & 19,859177 & $-2,3966333$ \\
\hline
\end{tabular}

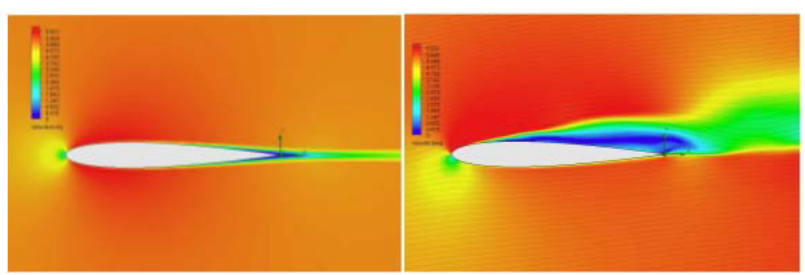

Fig. 9. NACA0012 Velocity distribution and flow lines for the angle of: a) $0^{\circ}$, b) $10^{\circ}$. 
In Fig. 9 despite velocity distribution there is also added flowing lines illustrating air behavior at descent of the airfoil. We can see jet, which is "glued" to convex part of the wing. On steam down edge is creating elevated pressure zone, as shown in Fig. 9a and 10a. This phenomenon is desirable.

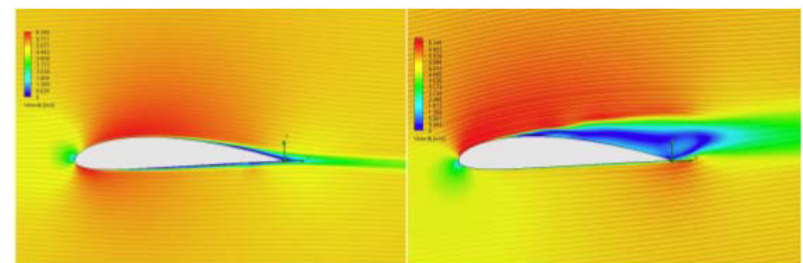

Fig. 10. NACA4415 Velocity distribution and flow lines for the angle of: a) $0^{\circ}$, b) $10^{\circ}$.

Fig. 9b again shows the velocity distribution around the airfoil, assisted flow lines to illustrate the behavior of the jet. Clearly stall zone. The angle for the lift reaches the highest value is called the critical angle. In Fig. 10b is shown the velocity distribution of an angle of $10^{\circ}$, the in the separation area speed falls to zero, while in the convex part of airfoil maximum value of the velocity is higher than in the case of a symmetric panel.

\subsection{Results comparison from Flow Simulation and Xfoil}

The results of the lift coefficient $C_{l}$ are shown in Tables 3 and 4 and compared with the values taken from the website airfoiltools.com, the site is a good source of information on the airfoils.

Table 3. Simulation - NACA0012 surface parameters.

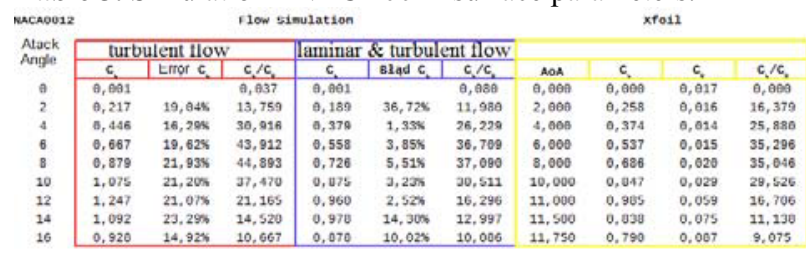

Table 4. Simulation - NACA4415 surface parameters.

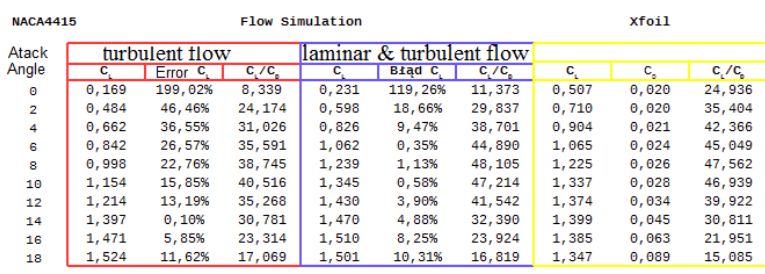

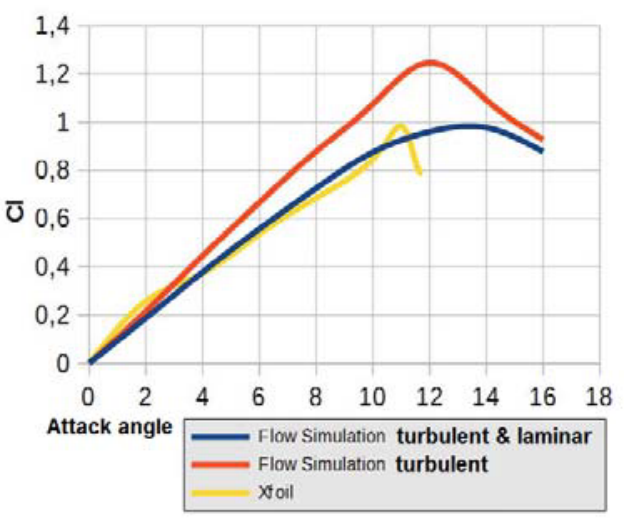

Fig. 11. NACA0012 $C_{l}$ vs. attack angle.

All currently available charts on this site have been made with the application Xfoil, written by researchers at the Massachusetts Institute of Technology, the application is a professional tool for design and analysis of wing.

Figure 11 compares the results of the Flow Simulation for laminar turbulent and only turbulent flow of NACA0012 symmetrical panel with the values from Xfoil program. Laminar and turbulent flow to angle of $10^{\circ}$ gives results consistent with the program, lift coefficient is linear. $13^{\circ}$ angle is a critical angle of attack for this flow.

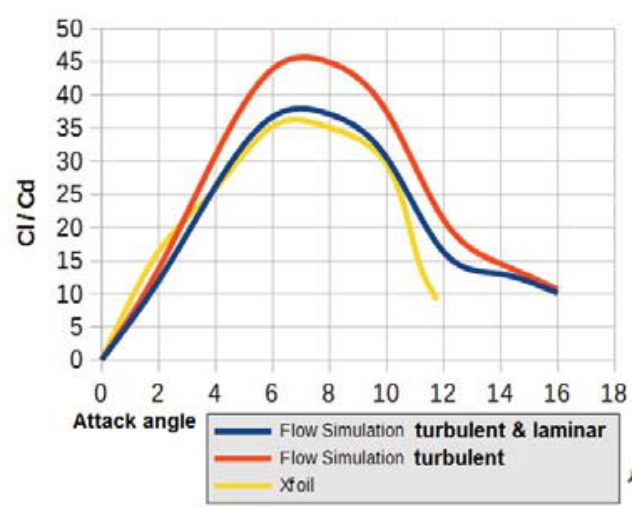

Fig. 12. NACA0012 $C_{l} / C_{D}$ vs. attack angle.

Figure 12 shows the ratio of $C_{l}$ to $C_{d}$ with respect to the attack angle for the airfoil NACA 0012. The highest value read from the graph determines the optimum angle which should be set for the airfoil to maximize aerodynamic force, in this case $7^{\circ}$. The value of the $C_{d}$ was taken from www.airfoiltools.com. We can see the convergence of the results of flow laminar and turbulent analysis results of Xfoil. 


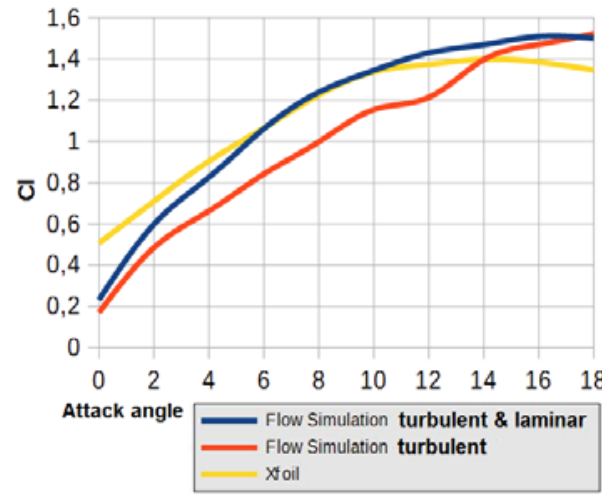

Fig. 13. NACA $4415 C_{l}$ vs. attack angle.

Figure 13 shows the results for the $C_{l}$ coefficient NACA 4415 airfoil. Comparing the values from Tables 3 and 5 showing that predicted lift coefficient is higher for this unsymmetrical airfoil. For angle equal to $8-9^{\circ}$ the turbulent-laminar flow chart is almost linear, with increasing angle of attack values of gain coefficient $C_{l}$ decreases, while increasing the drag coefficient $C_{d}$. The consequence is to break the jet illustrated in Figure $10 \mathrm{~b}$. From the Fig. 14 can be read the optimum angle of attack equal to 9 degrees. The angle value coincides with the simulation results from Xfoil program. Again, we can see that the analysis of turbulent flow does not give satisfactory results, although for higher value of the angle results begin to cover what may well be a matter of chance.

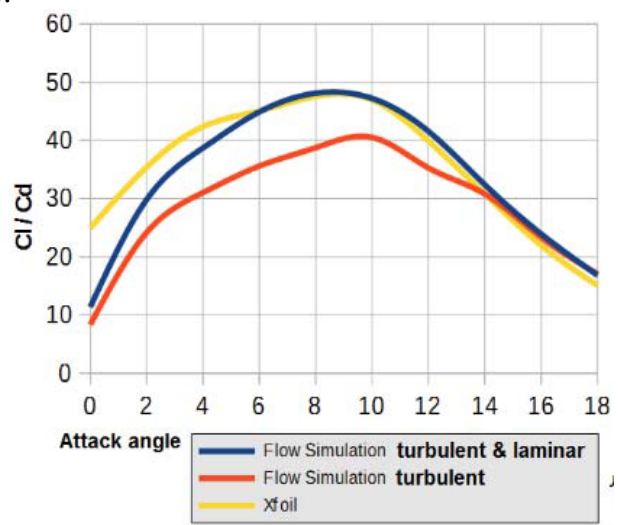

Fig. 14. NACA $4415 C_{l} / C_{D}$ vs. attack angle.

\subsection{Calculation of airfoil aerodynamic force of Darrieus turbine}

The optimum angle of attack for the airfoil NACA0012 is 7 degrees, the value of the resultant force is 0,012 [N] for the NACA 0045 at an angle of 9 degrees East is $0.023[\mathrm{~N}]$. Figure 15 is a graphical representation of the results obtained as a ratio of aerodynamic force to attack angle. For optimum attack angles of simulated individual airfoils data give consistent results analysis Xfoil.

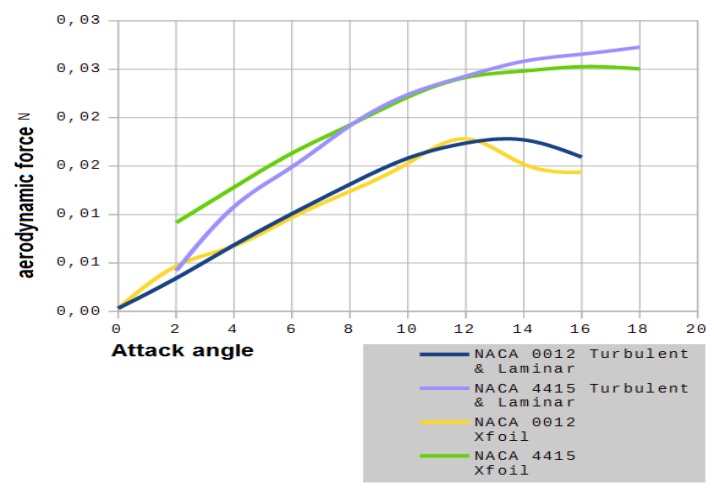

Fig. 15. Aerodynamic force - summary results.

On the basis of the results, decided to use the NACA4415 airfoil. For the project Darrieus vertical wind turbine key parameter is generated lift, the only one option to be considered is the use of asymmetric wing of attack angle $9^{\circ}$.

\subsection{Lenz2 turbine}

Leaving the core design: shaft, hub bearings, stator and the rotors, developed a second model type Lenz2. Darrieus turbine using lift is very efficient compared to the turbine Savonius's, but has problems with self-start. While Savonius's turbine trouble-free start it does not reach higher speeds, so Lenz 2 model seems to be the ideal solution, combining the two concepts.

Figure 16 illustrates the pressure distribution of airfoil Lenz2 at angle of attack $9^{\circ}$. According to the turbine author Ed Lenz, after many trials and tests, he was able to determine the angle of attack for the turbine achieves the highest performance, quite accidentally $9^{\circ}$ angle coincides with the angle unsymmetrical airfoil. It is showing a low pressure area at the front, upper part of panel.

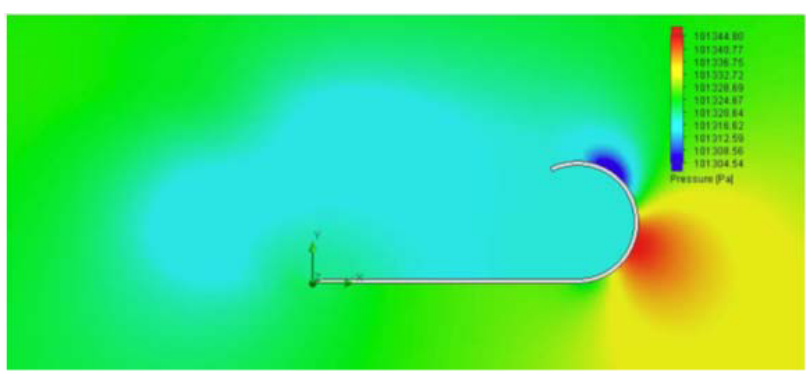

Fig. 16. The turbine Lenz2 airfoil - pressure distribution for angle of attack $9^{\circ}$.

Figure 17 shows the velocity distribution on flow lines. After wind left from streamlined side of airfoil swirls are created accordance with turbulent flow characteristics. In place of the lower pressure showing that the speed reaches the maximum value. 


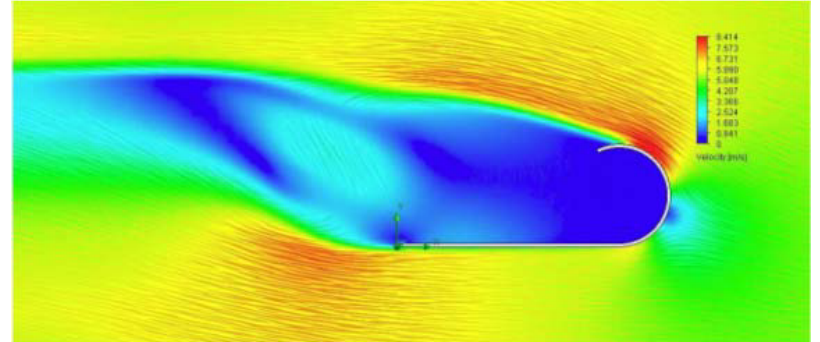

Fig. 17. The turbine Lenz2 airfoil - speed distribution for angle of attack $9^{\circ}$.

Based on flow simulation it can be seen that the airfoil exhibits aerodynamics.

Figure 18 illustrates the behaviour of the air mass entering the turbine and around it. The arrows in the figure are the velocity vectors of blowing air showing the direction and value. The rotational speed of the turbine

$\omega=100 \mathrm{rev} / \mathrm{min}$, the wind speed is $v=5 \mathrm{~m} / \mathrm{s}$. The greater the wind speed decrease in the turbine, the turbine use it better. On the front parts of the aerofoil can be seen that the velocity reaches a maximum value.

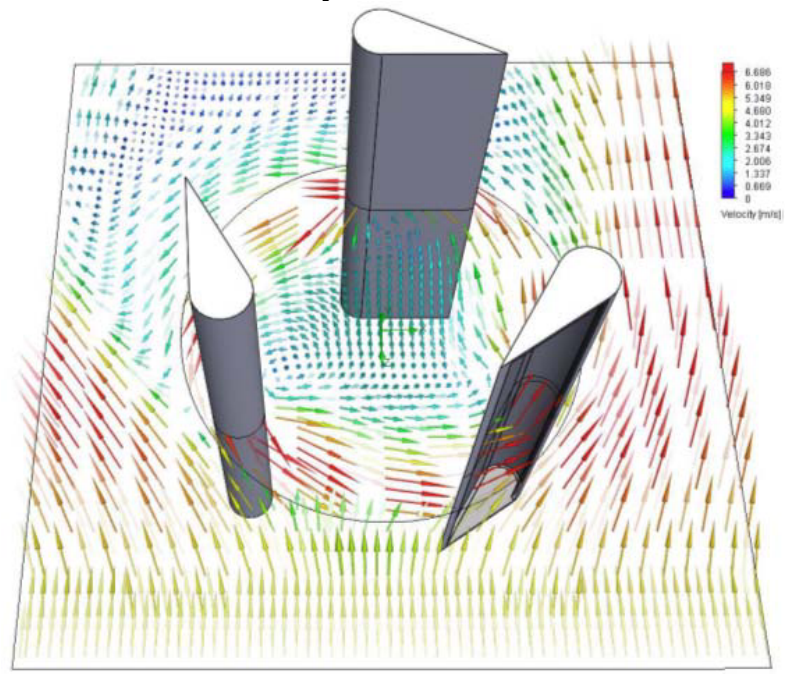

Fig. 18. The turbine Lenz2 airfoil - distribution of wind speed.

Strength analysis of bent sheet is taken incumbent on the plating of aluminum stiffeners and attachments weighing a total of $4.5 \mathrm{~kg}$. SolidWorks automatically created shell element based on the characteristics of the model (see Fig. 19).

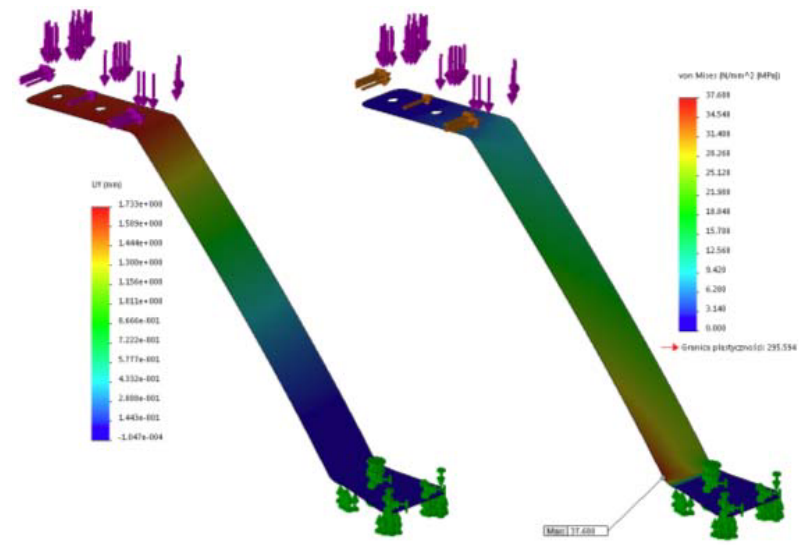

Fig. 19. The maximum stress and displacement - results.
The figure 20 shows the results of analysis for adverse winds, the results are satisfactory, although tension rose nearly doubled to $61.8[\mathrm{MPa}]$ but still are far below the yield stress, which is below $26 \%$, good supply. Vertical movement also increase, nearly doubled, now is $3 \mathrm{~mm}$, which still does not constitute grounds for concern. When the structure is assembled gently, and when working in difficult conditions, lowering the wing of 2-3 mm does not matter.
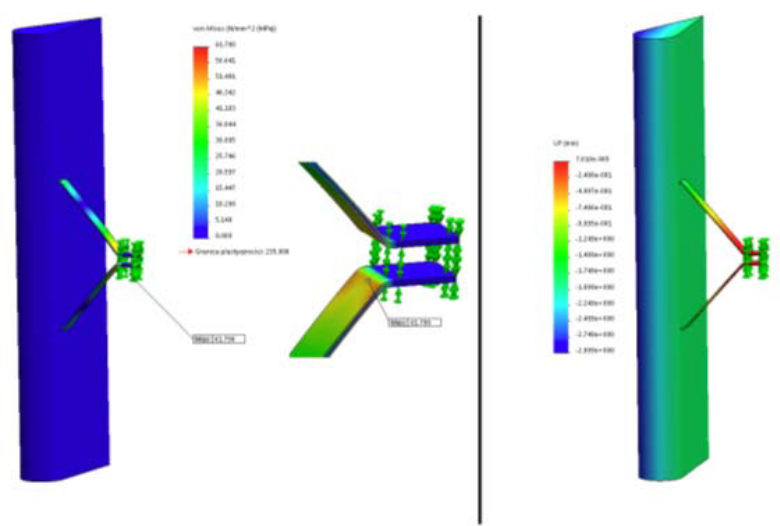

Fig. 20. Results of the analysis - the maximum stress and displacement under wind pressure.

\section{Summary and conclusions}

A rapidly growing research area of using wind power turbines provides great opportunities for research and development of existing ones and force to create new solutions in this field. Darrieus turbine project had been initial idea, but after building 3D model and simulating aerodynamic, as the information exploration on it, we changed the model of the turbine to Lenz2. This was because, H-rotor Darrieus model did not give self-start assurance at low wind speed and the self-excitation was not reach at all. Turbine Lenz's combines the use of drag force and aerodynamic force. This turbine is also selfstarted at low wind speed and its wings can reach greater speed than the speed of the wind.

HAWT (Horizontal Axis Wind Turbine) turbines are used in the production of electricity on an industrial scale, but if we want to have a backyard system, which would help save on water heating or garden lighting, Lenz's turbine model is a good option. We can use for more research papers [7-11].

\section{References}

1. E. Hau, Fundamentals, Technologies, Application and Economics. Springer, (2000)

2. M. O. L. Hansen, Aerodynamics of Wind Turbines. Earthscan (2009).

3. M. Utkin, Młody technik 02 p. $26-29$ (2005),

4. Website http://airfoiltools.com/airfoil/

5. Website http://aquaponicfun.com/step-by-step/windturbine/

6. Research Institute for Sustainable Energy, RISE Information Portal-Windmill http://www.rise.org.au /info/Tech/wind .html 
7. H. Wisniewski, L. Plonecki, Proceedings of the 16th International Carpathian Control Conference (ICCC), 2015

8. J. Zwierzchowski, Edited by Zolotarev I., Radolf V. Proceedings of 22nd International Conference on Engineering Mechanics 2016 (Academy of Sciences of the Czech Republic, 2016)

9. M. Blasiak, R. Kotowski, Przeglad Elektrotechniczny, 85, 12, 2009

10. M. Blasiak, Edited by Zolotarev I., Radolf V. Proceedings of 22nd International Conference on Engineering Mechanics 2016 (Academy of Sciences of the Czech Republic, 2016)

11. L. Nowakowski, E. Miko, M. Skrzyniarz, Edited by Zolotarev I., Radolf V. Proceedings of 22nd International Conference on Engineering Mechanics 2016 (Academy of Sciences of the Czech Republic, 2016)

12. E. Miko, L. Nowakowski, L. Procedia Eng. 39 (2012b)

13. Z. Koruba, I. Krzysztofik, P. I. Mech. Eng. K-J. Multi-Body Dyn. 227, K1, 2013

14. J.E. Takosoglu, P.A. Laski, S. Blasiak, G. Bracha, D. Pietrala. Meas. Cont. 49, 2, 2016 